\title{
OPTIMIZATION OF SEQUENCING PROBLEM IN MANUFACTURING SYSTEM USING JOHNSON'S TECHNIQUE
}

\author{
Ashutosh Singh ${ }^{1}$, D. Jha ${ }^{2} \&$ Dhruv Kumar ${ }^{3}$
}

Abstract : A reconfigurable manufacturing system is specially designed around group families of product. In this paper, an approach (Johnson algorithm) is presented for selecting the optimal sequence plan of single product flow-line for manufacturing tasks. It could serve as an important tool for selecting an optimal sequence plan at the initial stage of manufacturing system and subsequent changes in products scope and facilities expansion, reduction and modification. A case study illustrates the proposed approach.

Key words: reconfigurable manufacturing system, process planning, machining time

\section{INTRODUCTION}

In order to globalization of market, today's manufacturing sector must be highly responsive that rapidly can respond in tune with current markets scenarios. In the mid of 1990, Reconfigurable Manufacturing Systems (RMS) were introduced to face with increasing global market surges, unanticipated product changes through reconfiguration at machine level and system level. Different manufacturing system require different approaches to sequence planning of manufacturing task. In traditional manufacturing system the machine tool are fixed and not modular. The process plans and planning functions are important links between the features of various generations of products /product families and the features, capabilities and configurations of manufacturing systems and its components throughout their respective life cycles. The relationships between process plans and both products characteristics and manufacturing systems attributes are closely intertwined. The efficient generation and reconfiguration of process plans is an important enabler for changeable and responsive manufacturing systems. It is obvious, based on the few research publication found in the field of sequence planning for RMS, that are remains many gaps, there is a need for a new sequence planning approaches for RMS that achieve dynamics process plan. In the past 3 decades there has been increasing efforts to develop and improve Computer Aided Process Planning (CAPP) systems that aid human process planners. Alting and Zhang (1989) and ElMaraghy (1993) provide comprehensive literature surveys on CAPP. ElMaraghy(2006) focuses on process plans and planning functions asthe important link between the features of generations of products/product families and the features, capabilities and configurations of manufacturing systems and components throughout their respective life cycles and emphasized the need for adapting process plans to the reconfiguration of both products and systems (Wiendahl et al. 2007). One of the other very few researches with regards to the application of process planning to the new paradigm of RMS is the work carried out by Ling et al. 2000b.

\section{PROBLEM DESCRIPTION AND FORMULATION}

Sequencing problem arise when we are concerned with situation where there is a choice as to the order in which a number of manufacturing tasks can be performed on different machine. In such case, the effectiveness is a function of the order or sequence in which the tasks are performed. A sequencing problem could involve jobs in manufacturing system, maintenance scheduling in a factory, and so forth. we shall consider the sequencing problem in respect of the jobs to be performed in a industry and study in the method of their solution. Such sequencing problems can be broadly divided in two groups. in the first one ,there are $\mathrm{n}$ jobs to be done, each of which requires processing on same or all of the $\mathrm{K}$ different machine. We can determine the effectiveness of each of the sequence that are technologically feasible (that is to say, those satisfying the restrictions on the order in which each jobs must be processed through the machine) and choose a sequence which optimizes the effectiveness.

\section{THE ASSUMPTIONS}

There are some general assumptions made to solve the sequencing problems for manufacturing system.

- The processing time on various machine are independent of the order in which different jobs are processed on them.

- The time taken by different jobs in going from one machine to another is negligible.

- A job once started on a machine would be performed to the point of completion uninterrupted.

\footnotetext{
${ }^{1}$ Department of Mechanical Engineering, JIMS Engineering Management Technical Campus, Gr. Noida -201308 India

${ }^{2}$ Department of Mechanical Engineering, JIMS Engineering Management Technical Campus, Gr. Noida -201308 India

${ }^{3}$ Department of Mechanical Engineering, JIMS Engineering Management Technical Campus, Gr. Noida -201308 India
} 
- A machine cannot process more than one job at a given point of time.

- A job would start on a machine as soon as the job and the machine on which it is to be processed are both free.

Sequencing problems can be solved by using the Gantt Chart and by applying Johnsons algorithms.

\subsection{Algorithm for solving sequencing problems: Johnsons Rule}

The method shall be discussed in respect of processing of $n$ jobs through (a) two machine (b) three machine

Processing $n$ jobs through 2 machines as mentioned earlier, we have the following information:

1) Only two machines are involved.

2) Each jobs is to be processed in the order $\mathrm{AB}$ so that first work would be performed on machine $\mathrm{A}$ and then on machine B.

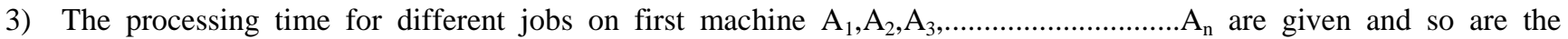
processing time on the second machine $\mathrm{B}_{1}, \mathrm{~B}_{2}, \mathrm{~B}_{3}$ $\mathrm{B}_{\mathrm{n}}$

With the objective to determine the sequence in which the jobs may be performed so that the total time taken is the minimum, we proceed as follows. Let

$\mathrm{A}_{\mathrm{i}}=$ time taken by jobs $\mathrm{i}$ on machine $\mathrm{A}$;

$\mathrm{B}_{\mathrm{i}}=$ time required by jobs $\mathrm{i}$ on machine $\mathrm{Bi}$;

$\mathrm{T}=$ total elapsed time for jobs $1,2,3 \ldots \ldots \ldots \ldots . . \mathrm{n}$; and

$T_{i}=$ idle time on machine $B$,from end of job i-1 to start of job i.

The objective is to determine the sequence $\mathrm{S}$ in which the $\mathrm{n}$ jobs may be performed so that $\mathrm{T}$ is minimized. We know that the total elapsed time, $\mathrm{T}$, is determined by the point of time at which the first job goes on machine $\mathrm{A}$ and the point of time on which the last job comes off machine B. At any moment of time, the machine B is either working or idle. The total time for which the machine $B$ has to work is $B_{i}$ (Which is determined by the given job times and has nothing to do with the sequence in which they are performed). Thus, because the first of the terms of the RHS of this equation is a constant, the problem is to minimize the second so the terms, the total idle time on machine B. If Dn (s) represents the total idle time on machine B for sequence $S$, the problem is that of findings a sequence $S^{*}$ of jobs $(1,2,3 \ldots \ldots . . . n)$ such that $\mathbf{D n}\left(\mathbf{S}^{*}\right)<\operatorname{Dn}\left(\mathbf{S}_{\mathbf{0}}\right)$ for any $\mathrm{S} 0$. Without proof, it may be stated that an optimal sequence is obtained by using the following rule.

Job J precedes job $J+1$ if $\operatorname{Min}\left(A_{j}, B_{j+1}\right)<\operatorname{Min}\left(A_{j+1}, B_{J}\right)$.

In operational terms, the algorithms can be stated in a stepwise manner as follows:

Step 1: Select the smallest processing time, considering $A_{1}, A_{2}, A_{3} \ldots \ldots \ldots \ldots \ldots . . . . A_{n}$ and $B_{1}, B_{2}, B_{3}, \ldots \ldots \ldots \ldots B_{n}$ together.

Step 2:

$>$ If the minimum is for $A_{r}$, that is to say, for the $\mathrm{r}^{\text {th }}$ job on machine $A$, do the $\mathrm{r}^{\text {th }}$ job the first.

$>$ If the minimum is for $B_{s}$, that is, for the $s^{\text {th }}$ job on machine $B$, do the $s^{\text {th }}$ job in the end.

$>$ In case of a tie between $A_{r}$ and $B_{s}$, perform the $r^{\text {th }}$ job first and $s^{\text {th }}$ job the last.

$>$ If there is a tie between 2 or more timings in either of the series, select either of the jobs involved and perform the first , accordingly as the tie is in $\mathrm{A}_{1}, \mathrm{~A}_{2}, \mathrm{~A}_{3} \ldots \ldots \ldots \ldots \ldots . . \mathrm{A}_{\mathrm{n}}$ or $\mathrm{B}_{1}, \mathrm{~B}_{2}, \mathrm{~B}_{3}, \ldots \ldots \ldots \ldots \ldots \mathrm{B}_{\mathrm{n}}$.

Step 3: After the jobs (s) has /have been assigned, apply steps 1 and 2 to the reduced set of processing times obtained by deleting the machine times corresponding to the job(s) already assigned.

Step 4: Continue in this manner until all jobs are assigned. The sequence of the jobs to be performed obtained in this way shall be optimal, involving the least aggregate time for completion of the jobs.

\subsection{Processing $n$ jobs through 3 machines}

No general solution is available for the sequence problem of processing $\mathrm{n}$ jobs through three machines. However, we do have a method applicable under the condition that no passing of jobs is permissible ( that is to say, the same order over each machine is maintained) and if either or both the following conditions is / are satisfied.

For three machines $\mathrm{M}_{1}, \mathrm{M}_{2}, \mathrm{M}_{3}$ on which some jobs are to be performed in the order $\mathrm{M}_{1} \mathrm{M}_{2} \mathrm{M}_{3}$.

Condition 1 :The minimum of the time for different job on machine $\mathrm{A}$ is at least equal to the maximum of the time of different jobs on machine $\mathrm{B}$.

Condition 2 :The minimum of the time of various jobs on machine $\mathrm{C}$ is at least equal to the maximum of the times of the different jobs on machine B.If Min $A_{i}$ represents the least of the job times on machine A, Min $C_{i}$ represents the least of the job times on machine $\mathrm{C}$, and Max $\mathrm{Bi}$ indicates the largest of the job times on machine $\mathrm{B}$, then if either Min $\mathrm{A}_{\mathrm{i}}>\mathrm{Max}_{\mathrm{i}}$ or Min $C_{i}>\operatorname{Max} B_{i}$, or both are satisfied then the following method can be applied.

The method

Step 1 replace the given problem with an equivalent involving $\mathrm{n}$ jobs and 2 fictitious machines $\mathrm{G}$ and $\mathrm{H}$, define the corresponding processing time $\mathrm{G}_{\mathrm{i}}$ and $\mathrm{H}_{\mathrm{i}}$ as follows:

$\mathrm{G}_{\mathrm{i}}=\mathrm{A}_{\mathrm{i}}+\mathrm{B}_{\mathrm{i}} \quad(\mathrm{i}=1,2,3, \ldots \ldots \ldots \ldots . . \mathrm{n})$, and

$\mathrm{H}_{\mathrm{i}}=\mathrm{B}_{\mathrm{i}}+\mathrm{C}_{\mathrm{i}} \quad(\mathrm{i}=1,2,3, \ldots \ldots \ldots \mathrm{n})$

Thus, for the job1, $\mathrm{G}_{1}=\mathrm{A}_{1}+\mathrm{B}_{1}, \mathrm{H}_{1}=\mathrm{B}_{1}+\mathrm{C}_{1}$; for the job 2, $\mathrm{G}_{2}=\mathrm{A}_{2}+\mathrm{B}_{2}, \mathrm{H}_{2}=\mathrm{B}_{2}+\mathrm{C}_{2} \ldots \ldots \ldots \ldots \ldots . . .$. and so on. 
Step 2 to the problem obtained in step 1, apply the method discussed for processing $n$ jobs through 2 machine. The optimal sequence resulting from this shall also be optimal for the given (original) problem. The schematic of the method is given in figure 1. (Schematics Presentation of the Algorithm for processing $n$ Jobs through 2 Machines A, B and C in order ABC).

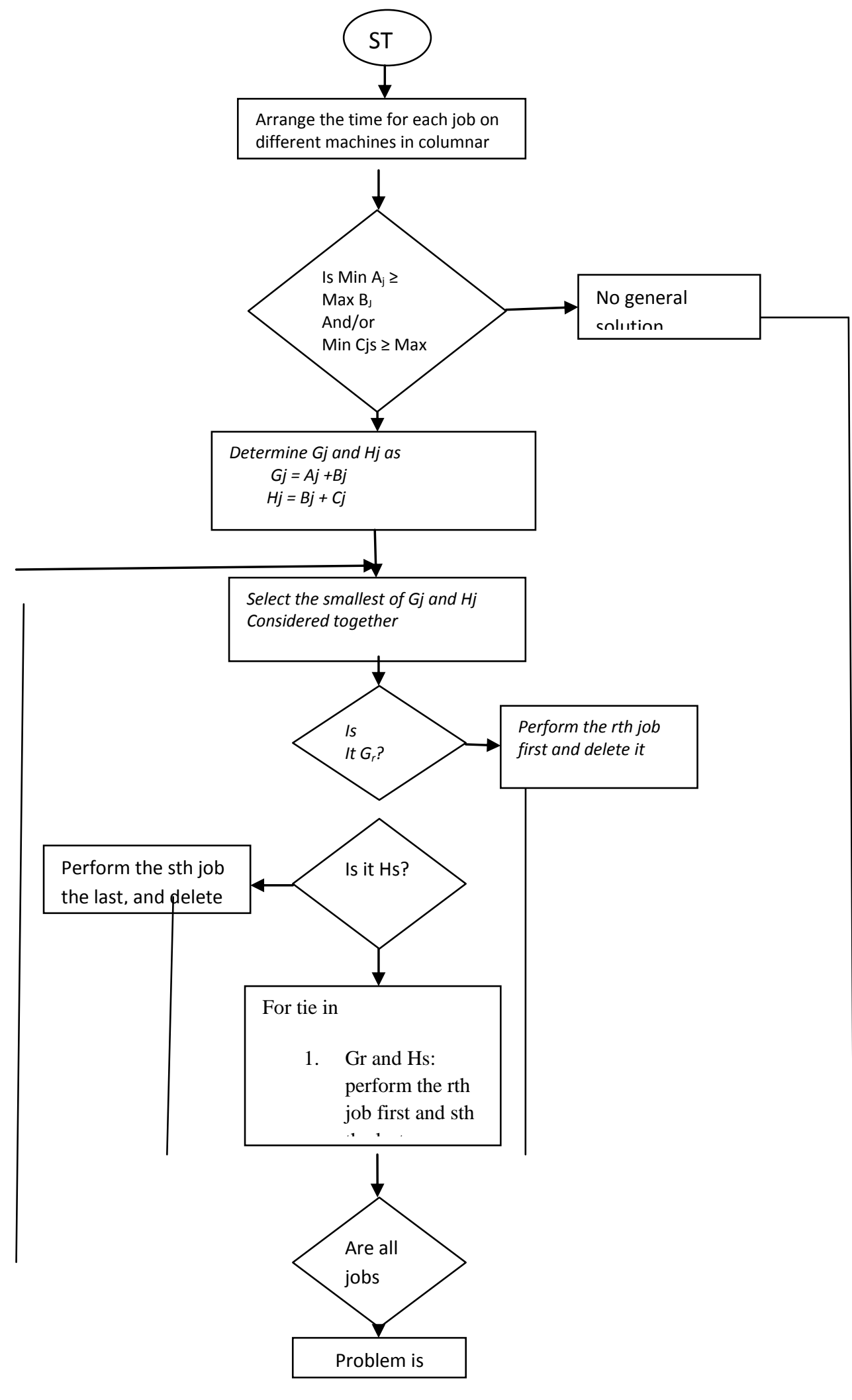




\subsection{Case study}

The following data regarding the processing times of some jobs on three machines I,II and III. The order of processing is I-IIIII. Determine the sequence that minimizes the total elapsed time (T)

\begin{tabular}{|l|l|l|l|}
\hline & Machine I & Machine II & MachineIII \\
\hline Job & Processing time(Hours) & Processing time(Hours) & Processing time(Hours) \\
\hline A & 3 & 4 & 6 \\
\hline B & 8 & 3 & 7 \\
\hline C & 7 & 2 & 5 \\
\hline D & 4 & 5 & 11 \\
\hline E & 9 & 1 & 5 \\
\hline F & 8 & 4 & 6 \\
\hline G & 7 & 3 & 12 \\
\hline
\end{tabular}

According to give information,

Min $\mathrm{I}_{\mathrm{i}}=3$

Max $\mathrm{II}_{\mathrm{i}}=5$; and

Min $\mathrm{III}_{\mathrm{i}}=5$

Clearly since Min $\mathrm{III}_{\mathrm{i}}=$ Max $\mathrm{II}_{\mathrm{i}}$, the second of the condition specified is met. Now, we can solve the problem as follows.

\begin{tabular}{|l|l|l|}
\hline Job & $\mathrm{G}_{\mathrm{i}}\left(=\mathrm{I}_{\mathrm{i}}+\mathrm{II}_{\mathrm{i}}\right)$ & $\mathrm{H}_{\mathrm{i}}\left(=\mathrm{II}_{\mathrm{i}}+\mathrm{III}_{\mathrm{i}}\right)$ \\
\hline A & 7 & 10 \\
\hline B & 11 & 10 \\
\hline C & 9 & 7 \\
\hline D & 9 & 16 \\
\hline E & 10 & 6 \\
\hline F & 12 & 10 \\
\hline G & 10 & 15 \\
\hline
\end{tabular}

According to this, there are two optimal sequences. They are $\mathrm{S}_{1}: \mathrm{A} \quad \mathrm{D} \quad \mathrm{G} \quad \mathrm{B} \quad \mathrm{F} \quad \mathrm{C} \quad \mathrm{F}$

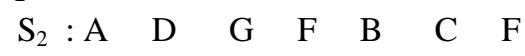

\section{CONCLUSION}

In the present study, a novel approach is proposed for sequence planning of a single product flow-line RMS using Johson algorithm. This study will be very much helpful in planning of manufacturing tasks at initial stage or at any new demand scenarios. In the future, other metaheuristics can be employed for optimisation of process plan in RMS with multiple objectives.

\section{REFERENCES}

[1] Alting, L. and Zhang, H., Computer aided process planning: the state-ofthe- art survey. Int. J. Prod. Res., 1989, $27,553-585$.

[2] ElMaraghy, H.A., Evolution and future perspective of CAPP. Annls CIRP, 1993, 42, 739-751.

[3] ElMaraghy, H.A., Reconfigurable process plans for reconfigurable manufacturing. 3rd International CIRP Conference in Digital EnterpriseTechnology, Setu' bal, Portugal, 18-20 September 2006 (Keynote paper).

[4] Wiendahl, H.-P., ElMaraghy, H.A., Nyhuis, P., Za“ h, M.F., Wiendahl, H.-H., Duffie, N. and Kolakowski, M., Changeable manufacturing classification, design and operation. Annls CIRP, 2007, 56.Ling, C., Yip-Hoi, D. and Koren, Y., Hole pattern identification in gangspindle head design for reconfigurable machining systems. Proceedings of 2000 ASMT DET00: 26th Design Automation Conferences, Baltimore,Maryland, 2000a, pp. 2532.

[5] Ling, C., Yip-Hoi, D. and Koren, Y., Operation clustering in processplanning for reconfigurable machining system design. Proceedings of the2000 Japan-USA Flexible Automation Conference, Ann Arbor, Michigan,2000b, pp. 879-88 